\title{
Global trends in increasing the level of psychological protection during decompression in the context of NATO's international experience
}

\author{
Maria Yarmolchyk ${ }^{1, *}$ \\ ${ }^{1}$ Department of Aviation Psychology, National Aviation University, Kyiv, 03680, Ukraine
}

\begin{abstract}
Research background: World processes of society development are closely connected with many aspects and spheres. World peace, a life without war, is a global goal that is an international goal. An important role in this issue is played by servicemen who defend their country, while sacrificing their own health and lives. Research on the psychology of servicemen is necessary in general in all countries, because psychological disorders occur in absolutely everyone.

Coping is a strategy of behavior in complex stressful situations, which is chosen by servicemen to deal with stress. This is a kind of response of the psyche, which is an adaptive mechanism at the time of negative impact. The choice of coping strategies is determined by a number of personality traits that determine the dominant pattern of behavior of a particular serviceman during decompression.

Purpose of the article: is to study the personality traits of servicemen, which determine the choice of coping strategies during decompression activities.

Methods: research methods are theoretical (analysis, synthesis, generalization, systematization), empirical (surveys, observations, testing, interviews), methods of mathematical statistics (to establish the type of data distribution -Kolmogorov-Smirnov criteria, to establish connections Pearson's criterion, Student's criterion, multiple regression analysis Fischer's criterion).

Findings \& Value added: The personal determinants of the choice of coping strategies by servicemen during decompression are established. The obtained results of empirical research form the basis for the psychological technology of development of personal determinants of the choice of effective coping strategies of servicemen at the stage of decompression.
\end{abstract}

Keywords. Coping strategy; personal; determinants; servicemen

JEL Classification: I1; I10; I12; I18; H56

\footnotetext{
*Corresponding author: linkinfan357@ukr.net
} 


\section{Introduction}

The problem of choosing coping strategies by the military is especially acute today. Coping strategies are one of the mechanisms of psychological protection that increases the level of psychological resilience of the military. The activities of military units become especially important in conditions of instability in the world. The current state of affairs presents requirements that often exceed the psychological capabilities and resources of the military. This, in turn, creates a need for a special type of personality stable, socially active, with a high level of self-regulation and the ability to withstand pressure from adverse factors (Harvey M. et al., 2001)

The process of decompression is quite complex and is a form of psychological recovery for a long time were in combat conditions. Decompression consists of a set of measures of physical and psychological recovery of the serviceman's body, which is carried out in order to readapt to normal living conditions. Regardless of the name of the program, in NATO countries the process of "decompression" or TLD refers to measures (procedures) composition to "spin" or "wash away the mission" after a difficult and long stay in the war zone (Clark K et al.,1995; Alex Kocha et al.,2021)

In NATO countries, "decompression" refers to a short period of time in the third place (neither the area of hostilities nor the home), where personnel can relax. The main purpose of decompression is a gradual and consistent transition from the conditions of existence in the area of hostilities to civilian (peaceful) conditions of existence (residence) (Rasskazova E.I. 2013; Tremolada M. et al.; 2016).

Today in the foreign specialized literature there is no unity in the definition of "decompression" and its structure, but in most countries, there are significantly common elements that are characteristic of most programs. These include: providing assistance to servicemen, especially in established units for relaxation in a structured but not formal way; carrying out decompression measures in an ecologically clean place, in a place different (third place) from the area of hostilities, but under certain circumstances decompression measures may take place in the premises of the base location at the points of permanent deployment (Klemens Weigl et al., 2020).

Although Canada, France, Belgium and the Netherlands prefer to use hotel resorts, the United States and the United Kingdom prefer military facilities in third countries (Michael A. Hogg 2021).

Unlike the British decompression process, which lasts 36 hours and takes place at a preprepared military facility, the Canadian Armed Forces uses a civilian hotel. To date, the ideal duration of decompression has not been determined, and its definition is based on the principle of excessive workload on personnel (Daiva Alifanoviene et al. 2018)

One of the stages of decompression is psychodiagnostics, in the complex of which our study was conducted. It is important to note that how adaptive and productive the dominant coping strategy is depending on how quickly the military will be able to recover psychologically and overcome the consequences of hostilities. In the conditions of hostilities, constant tension and colossal psychological load there is a deformation of the personality. This is due to a number of factors. In particular, it is necessary to take into account the peculiarities of the war itself and its specifics. The fighting in eastern Ukraine is hybrid, with widespread use of psychological pressure, manipulation, advocacy, and misinformation. To date, this is causing an increase in psychogenic losses among personnel. The personality of a serviceman is undergoing changes in all areas (Aleksandrova L. 2008).

During decompression measures, it is found that more than $60 \%$ have signs of combat stress of varying severity. Thus, there are violations of behavioral self-regulation, uncontrolled aggression, panic attacks. Accordingly, the choice of a productive and effective coping strategy becomes impossible due to violation of personal characteristics. It is important to teach servicemen to act properly in a stressful situation, to be able to control the 
choice of the necessary coping. Active change of the situation by the serviceman should become more adaptive than adaptation to it. Positive coping strategies help to improve mental health, reduce risk factors for disease and mitigate their effects. Thus, successful coping strategies in difficult living conditions allow the serviceman to overcome life crises, severe stressful situations. Such strategies are generally related to the resource of the individual or the potential, the stock of its various structural and functional characteristics that provide general activities and specific forms of behavior, response, and adaptation (Billings A.G., Moos R.H., 1984).

\section{Methods}

The following diagnostic tools are used in the work: Questionnaire of self-control methods (adaptation of WCQ method) by R. Lazarus and S. Folkman in adaptation by T.L. Kryukova, E.V. Kuftiak, M.C. Zamyshlyaeva; personal questionnaire "SACS" (S. Hobfall); five-factor personality questionnaire; methods of multifactor study of R. Kettel's personality; Freiburg personal questionnaire; method of diagnosing the level of Spielberger-Khanin anxiety.

The study involved 150 servicemen of the Air Force, the Land Forces of the Armed Forces of Ukraine. Diagnosis was performed in three stages, during the fighters' decompression measures.

The experimental procedure included the following steps:

Psychodiagnostics material was collected.

Statistical processing of the obtained results was performed using the program SPSS21.0.

The expression of the personal characteristics outlined in the theoretical section, which influence the choice of coping strategies, is empirically tested.

It is established how personal qualities determine coping strategies of servicemen.

\section{Results}

As a result of the diagnosis of the personal characteristics of coping strategies in the military, it should be noted that there are links between the indicators of the methods. First, the distribution of data was determined using the Kolmogorov-Smirnov criterion. To perform regression analysis, it is first necessary to perform a correlation analysis to determine the significant correlations of independent variables with dependent ones. For indicators that have a normal distribution, Pearson's criterion was used for correlation analysis. Spearman's criterion was used for correlation analysis for indicators that deviate from the normal distribution.

Confrontation is associated with a number of personality traits, including emotional stability. The nature of the relationship is reversed, the correlation is significant at 0.05 . That is, the higher the level of emotional stability of servicemen, the less often they choose confrontation as the dominant strategy. Confrontation allows servicemen to withstand difficulties, especially in the context of a combat mission.

Confrontation and the scales of the five-factor questionnaire (subordination / dominance, trust / suspicion, understanding / misunderstanding, persistence / lack of persistence, carelessness / anxiety, sensitivity / insensitivity) have been found to be direct. If servicemen are dominant in the relationship, quite suspicious and hostile to the environment, do not show understanding, are anxious enough, then they will choose confrontation as the main strategy to combat stress. The self-control / impulsiveness scale has inverse relationships with this coping. The higher the level of impulsiveness, and the lower the level of self-control, the greater the likelihood of using confrontation in a tense situation.

The distancing strategy also has inverse correlations with emotional stability and diplomacy. So, if servicemen are able to control their emotions, feelings and experiences, 
then in a stressful situation they do not distance themselves from the problem but try to solve it in a more effective way and choose a productive coping strategy. The ability to find a way out of any situation, the use of diplomacy in resolving conflict situations reduces the likelihood of choosing distancing as the dominant strategy. Distancing is associated with the isolation of the individual. The more servicemen are isolated from their surroundings, lead a closed and alienated way of life, the more often they choose to distance themselves in a stressful situation. The desire to avoid undue attention and stay away from events increases the desire to separate, to distance oneself from the problem. Lack of perseverance means insufficient effort on the part of the military. They try to step aside, separate from their own experiences, placing the responsibility for the result on others. Thus, they use a distancing strategy to deal with stress, often deny having a negative experience, and refuse to work with psychologists. At the same time, servicemen have a sufficient level of volitional selfregulation, do not show internal feelings. Excessive predictability and tension are inversely correlated with distancing. If servicemen show carelessness and relaxed behavior, they are easy to get in touch with, try to actively deal with accumulated stress, and rarely distance themselves.

The self-control strategy has inversely correlated with neuroticism, irritability, reactive aggression, extra / introversion. The lower the level of neuroticism, irritability, reactive aggression, the more likely the choice of coping strategy of self-control as dominant.

Self-control correlates with the level of subordination of servicemen as individuals. That is, the less servicemen are prone to subordination, show dominant traits, the more often they choose the strategy of self-control as the main one. Such a personality trait as neatness is also related to this coping. In this case, this feature demonstrates the desire for order and comfort, perseverance in professional activities. The more conscientious and accurate the servicemen are in their actions, the more often they use coping of self-control, which they consider a means of resolving conflict and difficult situations.

There are direct correlations between self-control and scales: tension / relaxation, depression / emotional comfort, curiosity / conservatism. If servicemen feel emotionally comfortable, relaxed, realistically, and practically assess the situation, then they choose coping self-control to deal with stress.

The strategy of seeking social support has a direct correlation with the level of sociability. The more servicemen are prone to social contacts, have developed communication skills, the more they are prone to the choice of this coping.

The avoidance strategy is directly correlated with personality depression. That is, servicemen who have depressive traits tend to avoid unpleasant situations and run away from solving problematic issues. Avoidance correlates with masculinity. That is, the course of mental activity mainly on the male type determines the choice of avoidance as the main coping. The less balanced and open the military, the more often they use this coping. Low level of understanding, increased anxiety is the basis for choosing to avoid in a difficult situation.

Decision planning is inversely correlated with situational anxiety. Low levels of anxiety allow you to adequately assess the situation, identify areas of activity, build and think through a plan of action. In stressful situations, this allows you to concentrate and take responsibility for your own actions, consciously and clearly manage emotions. The strategy of taking responsibility is especially relevant and important for the military in leadership positions, as the commander must make decisions regardless of the situation. At the same time, the responsibility for the unit also rests with him, especially in a difficult situation, in particular in a combat situation. With a pronounced dominance and a high level of self-control, accuracy, which is a component of self-control, this strategy is the main one, as it allows you to control not only your own actions, but also the actions of others. If servicemen are prone to rivalry, this strategy is chosen more often and serves as a means of self-affirmation. If 
servicemen show depressive traits, are constantly tense, and avoid excessive attention, the strategy of taking responsibility in stressful situations is very rarely chosen. It can be noted that servicemen who show understanding in any situation, are persistent in their activities, quite expressive, easy to live, show interest in various aspects of activities, tend to use positive reassessment as the dominant coping strategy.

Soldiers tend to act in a stressful situation with the help of assertive actions, provided they are persistent, inquisitive, and understanding of the environment.

If respondents are prone to subordination, quite impulsive and inconsistent in their behavior, clear strategy, and action plan, they do not choose this strategy because they are not able to defend their rights and boundaries, do not speak openly about feelings and emotions.

Entering into social contact has inverse correlations with depression, subordination, respect for others. The more servicemen are prone to depression, do not feel emotional comfort, treat the environment with contempt, the less often they choose this coping. If the subjects are characterized as balanced and open to communication, persistent and inquisitive, artistic and sensitive in relationships with the environment, the strategy of social contact allows you to quickly and productively process the accumulated stress and deal with negative experiences, quickly solve existing problems.

Inverse relationships have been found between emotional stability, straightforwardness, artistry, predictability, and coping with caution. That is, the more unstable is the emotional sphere, expressed naivety, straightforwardness, even tactlessness, the less often this coping is used. Soldiers show excessive emotionality, indiscipline, do not predict the consequences of their own actions, tend to succumb to impulsive reactions. If the military has a high level of self-control and emotional calm, prefer order and comfort under any circumstances, then this strategy will be used as the main in a psychologically difficult situation.

Associated with the desire of servicemen to solve a stressful situation by attracting the attention of the environment. Inverse correlations between these indicators are traced. As a rule, such a strategy is unproductive, because the behavior is uncoordinated, and for the sake of attracting attention, often reckless actions are taken, which, on the contrary, lead to deterioration. Low level of self-control and inability to predict the consequences of their own behavior, provokes the use of this strategy in stressful situations. If servicemen are prone to anxiety, depression, show excessive interest in everything that is happening around, they tend to use impulsive actions to combat stress.

The escape strategy has direct links to subordination and accuracy as an indicator of the level of self-control. Escape, in this case, is used as a means of dealing with the problem, because servicemen with the above traits tend to avoid open conversations, are quite closed and not interested in the problems of others. If the mental activity proceeds according to the male type, and volitional regulation is at a high level, then escape is used less often and is not the leading strategy to combat negative factors. The ability to behave in a team, emotional endurance, caution and the ability to find a way out of any situation means a high level of diplomacy of servicemen. In this case, the escape is not the leading coping and is chosen by the subjects quite rarely.

Coping, which involves manipulative actions, has an inverse relationship with masculinity / femininity. Thus, if the predominance of masculine traits determines the low probability of manipulation in the fight against stress and, conversely, femininity determines the manipulative strategy to combat stress. This strategy is also about respecting others. The nature of the connection is reversed. That is, with a low level of respect for the environment, servicemen tend to use manipulative actions and techniques to help others solve their own needs and cope with stress. Lack of ability to predict the results of their behavior will increase the likelihood of using manipulative actions, because the consequences do not worry respondents. Given the position of separation in interaction, escape from participation in 
common affairs, a low level of respect for others and sufficient carelessness, the likelihood of using a strategy of manipulative action increases.

Aggressive actions, as a strategy to deal with stress, have inverse relationships with subordination and accuracy. If servicemen are prone to complete subordination, have a low level of voluntary self-regulation, the probability of choosing an aggressive strategy is low. Dominance, as a personality trait that is polar subordination, on the other hand, is associated with the choice of aggressive actions as dominant coping. Seeking attention is also associated with an aggressive strategy. If the military seeks recognition, to attract attention, then the use of aggression is a means to help stay in the spotlight. The level of trust has an inverse correlation with aggressive actions. The less servicemen trust the environment, treat everyone and everything with suspicion, the more often they choose this coping to deal with a stressful situation. Traits such as persistence and curiosity, with excessive severity, contribute to the use of aggressive actions to solve the problem situation.

Based on the established correlations, multiple regression analysis was performed and personal determinants of the choice of coping strategies were determined.

The formula for regression of confrontation has the following form:

$$
\begin{gathered}
\text { Confrontation }=-0.542(\mathrm{EC})+0.502(\mathrm{D})+0.405(\mathrm{H})+0.598(\mathrm{P})- \\
0.397(\mathrm{H})+0.304(\mathrm{HH})+0.387(\mathrm{C})+0.234(\mathrm{~T})+0.297(\mathrm{~N})
\end{gathered}
$$

According to the regression formula, it can be noted that the dependent variable "confrontation" is determined by the following variables: low level of emotional stability, low level of diplomacy and pronounced dominance, increased suspicion, low level of understanding, lack of persistence, sufficient level of self-control, severe anxiety and insensitivity.

The distress regression formula is as follows:

$$
\begin{aligned}
& \text { Distancing }=-0.667(\mathrm{EC})-0.548(\mathrm{D})-0.349(\mathrm{~K})+0.588(\mathrm{HC})- \\
& 0.575(\mathrm{H})+0.322(\mathrm{I})+0.312(\mathrm{P})++0.234(\mathrm{ENes})+0.297(\mathrm{H})
\end{aligned}
$$

According to the regression formula, it can be noted that the dependent variable "distancing" is determined by the following variables: low level of emotional stability and diplomacy, low level of sociability, expressed avoidance impressions, lack of persistence, high impulsiveness, predictability, low emotional stability, high levels of tension.

The self-control regression formula is as follows:

$$
\text { Self }- \text { control }=-0.515(\mathrm{H})-0.615(\mathrm{P})-0.315(\mathrm{RA})+
$$

$$
0.388(\mathrm{E})-0.472(\mathrm{P})-0.554(\mathrm{VA})+0.312(\mathrm{P})+0.336(\mathrm{EC})+0.597(\mathrm{C})
$$

According to the regression formula, it can be noted that the dependent variable "selfcontrol" is determined by the following variables: low levels of neuroticism, irritability and reactive aggression, extra / introversion, low level of subordination, lack of accuracy, pronounced relaxation, high level of emotional comfort and curiosity.

The social support search regression formula is as follows:

Social support search $=-0.634(\mathrm{C})$

According to the regression formula, it can be noted that the dependent variable "social support search" is determined by the independent variable - closed (high level). The more pronounced the isolation of the individual, the less he tends to choose this strategy of behavior as the main one.

The avoidance regression formula is as follows:

$$
\begin{aligned}
\text { Avoidance }= & 0.502(\mathrm{D})-0.531(\mathrm{BP})-0.212(\mathrm{~B})-0.335(\mathrm{M})- \\
& 0.373(\mathrm{P})-0.654(\mathrm{~B})
\end{aligned}
$$

According to the regression formula, it can be noted that the dependent variable "avoidance" is determined by the following variables: high depression, low balance and openness, pronounced masculinity, lack of understanding and low level of carelessness.

The decision planning regression formula is as follows:

$$
\text { Decision }=0,663(\mathrm{D})-0,743(\mathrm{SUP} / \mathrm{SPIV})+0,565(\mathrm{~A})+0,788(\mathrm{C})-
$$




$$
0,572(\mathrm{P})-0,754(\mathrm{D})-0,612(\mathrm{UU})-0,636(\mathrm{ST})
$$

According to the regression formula, it can be noted that the dependent variable "decision planning" is determined by the following variables: high dominance, propensity to compete, high accuracy, high level of self-control, low relaxation, low level of depression, pronounced attention, low level of situational anxiety. The positive revaluation regression formula is as follows:

$$
\text { Positive revaluation }=0.758(\mathrm{P})+0.643(\mathrm{H})+0.665(\mathrm{E})
$$

According to the regression formula, it can be noted that the dependent variable "Positive reassessment" is determined by the following variables: a high level of understanding, expressed persistence, high expressiveness.

The regression formula for assertive actions is as follows:

$$
\begin{aligned}
\text { Assertive actions }= & -0.869(\mathrm{P})+0.563(\mathrm{P})-0.763(\mathrm{VA})+0.623(\mathrm{H})+ \\
& +0.387(\mathrm{D})
\end{aligned}
$$

According to the regression formula, it can be noted that the dependent variable "assertive actions" is determined by the following variables: low level of subordination, high level of understanding, high level of persistence, accuracy and curiosity.

The formula for the regression of joining social contact is as follows:

Joining social contact $=-0.569(\mathrm{D})+0.642(\mathrm{~B})+0.642(\mathrm{VC})-0.562(\mathrm{P})+$ $0.686(\mathrm{PI})+0.575(\mathrm{H})+0.558(\mathrm{DP})-0.507(\mathrm{D})+0.680(\mathrm{~A})+0.578(\mathrm{C})$

According to the regression formula, it can be noted that the dependent variable "entry into social contact" is determined by the following variables: low level of depression, high level of balance and openness, low subordination, expressed respect for others, high persistence and curiosity, high level of emotional comfort and lack of depressive symptoms, expressed artistry and sensitivity. The formula for the regression of caution is as follows:

$$
\begin{gathered}
\text { Cautions }=-0.667(\mathrm{EC})-0.688(\mathrm{DP})+0.718(\mathrm{C})-0.601(\mathrm{~PB})+ \\
0.504(\mathrm{D})-0.674(\mathrm{~A})
\end{gathered}
$$

According to the regression formula, it can be noted that the dependent variable "caution" is determined by the following variables: low emotional stability, low level of diplomacy, high self.

The regression formula for impulsive actions is as follows:

$$
\begin{gathered}
\text { Impulsive actions }=-0.662(\mathrm{UU})+0.770(\mathrm{~B})-0.622(\mathrm{C})+ \\
0.651(\mathrm{~T})+0.676(\mathrm{D})+0.652(\mathrm{DP})
\end{gathered}
$$

According to the regression formula, it can be noted that the dependent variable "impulsive actions" is determined by the following variables: low level of avoidance of attention, high level of carelessness, low level of self-control, high anxiety, high level of depression, high curiosity. Escape regression is as follows:

Escape $=-0.678(\mathrm{P})-0.469(\mathrm{M})+0.688(\mathrm{PD})-0.557(\mathrm{P})+0.687(\mathrm{~A})(12)$

According to the regression formula, we can note that the dependent variable "escape" is determined by the following variables: low level of straightforwardness, masculinity, low subordination, misunderstanding and a pronounced lack of accuracy.

The regression formula for manipulative actions is as follows:

Manipulative actions $=0,234(\mathrm{M})-0,727(\mathrm{PDI})-0,658(\mathrm{~PB})+0,548(\mathrm{~T})(13)$

According to the regression formula, it can be noted that the dependent variable «manipulative actions" is determined by the following variables: low level of masculinity, low level of respect for others, low level of carelessness, high anxiety.

The regression formula for antisocial actions is as follows: 0.757 (DEC)

According to the regression formula, it can be noted that the dependent variable "antisocial actions" is determined by the following variables: high levels of tension and depression.

The regression formula for aggressive actions is as follows:

$$
\text { Aggressive actions }=-0.657(\mathrm{P})+0.680(\mathrm{PU})-0.658(\mathrm{D})-0.562(\mathrm{~A})+
$$




$$
0.594(\mathrm{H})+0.689(\mathrm{DP})
$$

According to the regression formula, it can be noted that the dependent variable "Aggressive actions" are determined by the following variables: low level of subordination, pronounced search for attention, low level of trust, lack of accuracy, high level of persistence, expressed curiosity.

\section{Discussion}

Based on the performed mathematical analysis, personal determinants for each coping are established. According to the obtained data, it can be noted that the dependent variable:

"confrontation" is determined by the following variables: low level of emotional stability, low level of diplomacy and pronounced dominance, increased suspicion, low level of understanding, lack of persistence, sufficient level of self-control, pronounced anxiety and insensitivity.

"distancing" is determined by the following variables: low level of emotional stability and diplomacy, low level of sociability, pronounced avoidance of impressions, lack of persistence, high impulsivity, predictability, low emotional stability, high level of tension.

"self-control" is determined by the following variables: low levels of neuroticism, irritability and reactive aggression, extra / introversion, low levels of subordination, lack of accuracy, marked relaxation, high levels of emotional comfort and curiosity.

"search for social support" is determined by an independent variable - closed (high level). The more pronounced the isolation of the individual, the less he tends to choose this strategy of behavior as the main one.

"avoidance" is determined by the following variables: high depression, low balance and openness, pronounced masculinity, lack of understanding and low level of carelessness.

"decision planning" is determined by the following variables: high dominance, propensity to compete, high accuracy, high level of self-control, low relaxation, low level of depression, pronounced search for attention, low level of situational anxiety.

"positive reassessment" is determined by the following variables: high level of understanding, persistence, high expressiveness.

"assertive actions" are determined by the following variables: low level of subordination, high level of understanding, high level of persistence, accuracy and curiosity.

"social contact" is determined by the following variables: low level of depression, high level of balance and openness, low subordination, expressed respect for others, high persistence and curiosity, high level of emotional comfort and lack of depressive symptoms,

"caution" is determined by the following variables: low emotional stability, low diplomacy, high self-control, low predictability, high depression, low artistry.

"impulsive actions" are determined by the following variables: low

"escape" is determined by the following variables: low level of straightforwardness, masculinity, low subordination and low subordination.

"manipulative actions" are determined such variables: low level of masculinity, low level of respect for others, low level of carelessness, high anxiety.

"antisocial actions" are determined by the following variables: high level of tension and depression.

"aggressive actions" are determined by the following variables: low level of subordination, pronounced search for attention, low level of trust, lack of accuracy, high level of persistence, expressed curiosity.

\section{Conclusion}

Thus, based on the results of the correlation and multiple regression analysis, the personal 
determinants of the choice of coping strategies during decompression were established: emotional stability / instability, straightforwardness / diplomacy, subordination / dominance, trust / suspicion, understanding / misunderstanding, persistence / lack of persistence, selfcontrol / impulsivity, impulsivity / impulsivity. insensitivity, isolation / sociability, avoidance / search for impressions, foresight / carelessness, tension / relaxation, neuroticism, irritability, reactive aggression, extra / introversion, accuracy / lack of accuracy, depression / emotional comfort, curiosity / conservatism, openness femininity, anxiety / carefreeness, rivalry / cooperation, avoidance / search for attention, situational anxiety, expressiveness / practicality, curiosity / realism, respect for others / self-esteem, sensitivity / insensitivity, artistry / lack of artistry. A number of personality traits influence the choice of coping strategy during a stressful situation, determine the pattern of behavior and the overall strategy of processing negative experiences. Knowing these determinants, it is possible to develop and implement psychological technology for the development of personal determinants of choosing effective coping strategies of servicemen at the stage of decompression, which will allow productive combat experience, improve psychological training of soldiers, and increase psychological stability of servicemen.

\section{References}

1. Alifanoviene, D., Sapelyte, O., \& Gerulaitis, D. (2018). Reconstruction of the context of coping with occupational stress experienced by specialists of social welfare professions in socially and culturally diverse environment. Social welfare: interdisciplinary approach, 2(8), 68-78.

2. Alonso-Tapia, J., Rodríguez-Rey, R., Garrido-Hernansaiz, H., Ruiz, M., \& Nieto, C. (2019). Coping, personality and resilience: Prediction of subjective resilience from coping strategies and protective personality factors. Behavioral Psychology/Psicologia Conductual, 27(3), 375-389.

3. Billings, A. G., \& Moos, R. H. (1984). Coping, stress, and social resources among adults with unipolar depression. Journal of personality and social psychology, 46(4), 877-891.

4. Brew, F. P., \& Cairns, D. R. (2004). Do culture or situational constraints determine choice of direct or indirect styles in intercultural workplace conflicts?. International Journal of Intercultural Relations, 28(5), 331-352.

5. Clark, K. K., Bormann, C. A., Cropanzano, R. S., \& James, K. (1995). Validation evidence for three coping measures. Journal of Personality Assessment, 65(3), 434-455.

6. Fisher, D. M., \& Law, R. D. (2021). How to choose a measure of resilience: An organizing framework for resilience measurement. Applied Psychology, 70(2), 643-673.

7. Harvey, M., Speier, C., \& Novecevic, M. M. (2001). A theory-based framework for strategic global human resource staffing policies and practices. International Journal of Human Resource Management, 12(6), 898-915.

8. Hogg, M. A. (2021). Self-uncertainty and group identification: Consequences for social identity, group behavior, intergroup relations, and society. In Advances in Experimental Social Psychology (Vol. 64, pp. 263-316). Academic Press.

9. Chen, G. M. (1992). Communication adaptability and interaction involvement as predictors of cross-cultural adjustment. Communication Research Reports, 9(1), 33-41.

10. Khurtenko, O., Bereziak, K., Khavula, R., Vdovichenko, O., Onishchenko, N., \& Liebiedieva, S. (2020). Psychological Analysis of Occupational Conditions in Extreme Environments and the Structure of Non-Standard Situations. BRAIN. Broad Research in Artificial Intelligence and Neuroscience, 11(4), 132-148. 
11. Koch, A., Yzerbyt, V., Abele, A., Ellemers, N., \& Fiske, S. T. (2021). Social evaluation: Comparing models across interpersonal, intragroup, intergroup, several-group, and many-group contexts. Advances in Experimental Social Psychology, 63, 1-68.

12. Lazarus, R. S., \& Folkman, S. (1984). Stress, appraisal, and coping. Springer publishing company.

13. Tremolada, M., Bonichini, S., \& Taverna, L. (2016). Coping strategies and perceived support in adolescents and young adults: predictive model of self-reported cognitive and mood problems. Psychology, 7(14), 1858.

14. Rasskazova E.I. (2013). Koping-strategii v strukture deyatel'nosti i samoregulyacii:psihometricheskie harakteristiki i vozmozhnosti primeneniya metodiki cope [Coping strategies in the structure of activity and self-regulation: psychometric characteristics and the possibility of applying the technique]. Psihologiya. Zhurnal VSh 'E - Psychology. HSE Journal/Vol. 10 (1), 82-118. [In Russian].

15. Weigl, K., \& Ponocny, I. (2020). Group Sequential Designs Applied in Psychological Research. Methodology, 16(1), 75-91. 